\title{
ERRATUM
}

\section{The Circulate architecture: avoiding workflow bottlenecks caused by centralised orchestration}

\author{
Adam Barker · Jon B. Weissman · Jano I. van Hemert \\ Published online: 5 March 2009 \\ (C) Springer Science+Business Media, LLC 2009 \\ Erratum to: Cluster Comput \\ DOI 10.1007/s10586-009-0072-4
}

In all versions of the original article, Fig. 3 was printed incorrectly (lines 3-6). Figure 3 as a whole should read exactly as follows:

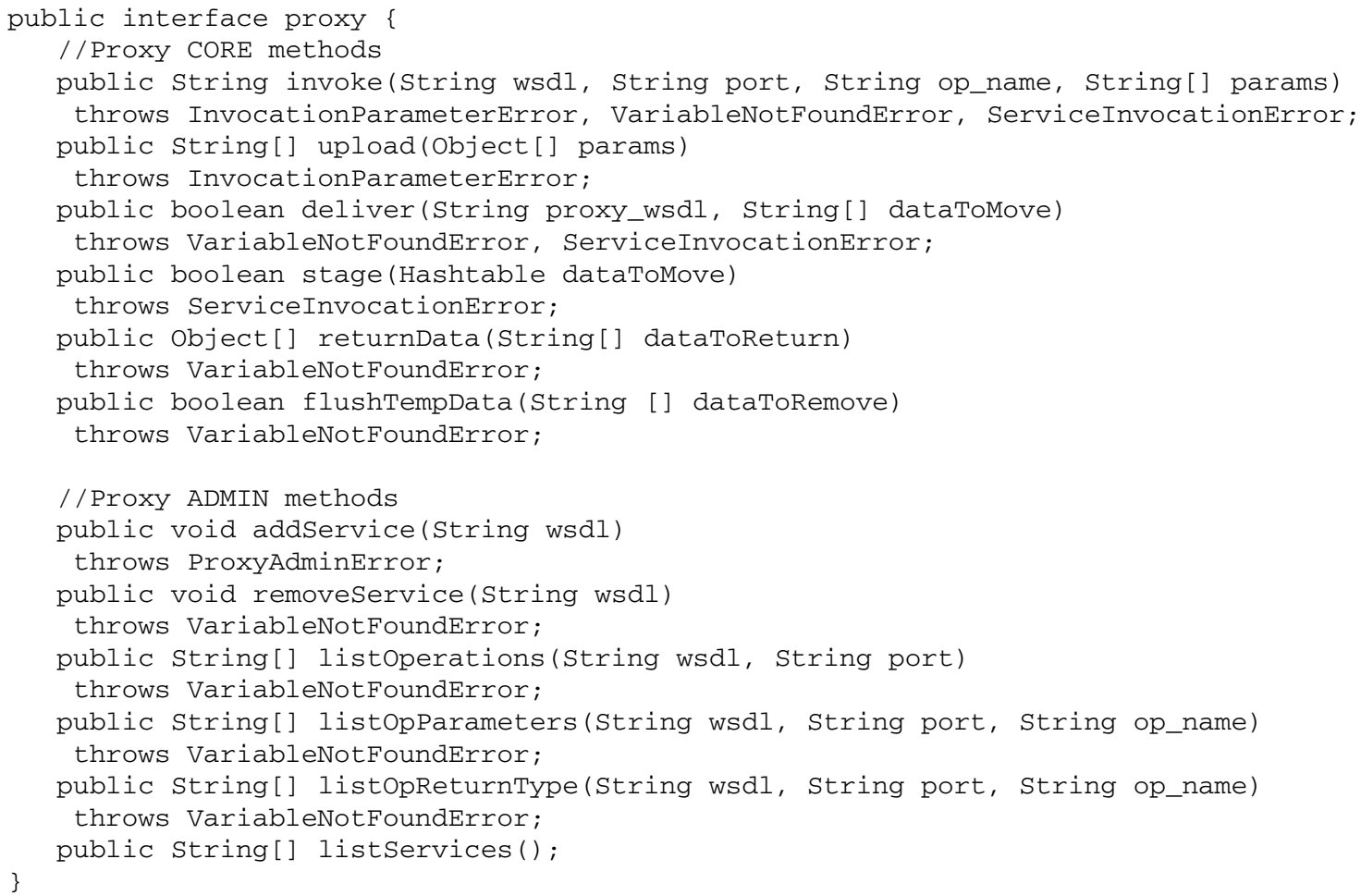

Fig. 3 WS-Circulate Proxy API

The online version of the original article can be found under doi:10.1007/s10586-009-0072-4.

\section{A. Barker $(\bowtie)$}

Department of Engineering Science, University of Oxford, Oxford, UK

e-mail: adam.barker@eng.ox.ac.uk
J.I. van Hemert

NeSC, School of Informatics, University of Edinburgh,

Edinburgh, UK

e-mail: j.vanhemert@ed.ac.uk

J.B. Weissman

University of Minnesota, Minneapolis, MN, USA

e-mail: jon@cs.umn.edu 